\title{
\begin{tabular}{l} 
Journal homepage: $\underline{w w}$.eurjehem.com \\
\hline
\end{tabular}
}

\section{M sub-shell X-ray fluorescence cross-section measurements in high Z elements with X-ray tube photon source}

\author{
Sheenu Gupta, Gurpreet Kaur, Himani Bansal, Vijay Kumar Mittal, and Raj Mittal * \\ Nuclear Science Laboratories, Physics Department, Punjabi University, Patiala-147002, India \\ *Corresponding author at: Nuclear Science Laboratories, Physics Department, Punjabi University, Patiala-147002, India. \\ Tel.: +91.941.7284302. Fax: +91.175.3046163. E-mail address: rmsingla@yahoo.com (R. Mittal).
}

\section{ARTICLE INFORMATION}

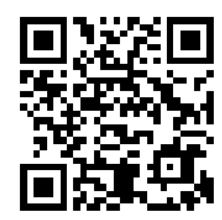

DOI: 10.5155/eurjchem.5.2.363-369.1016

Received: 16 January 2014

Received in revised form: 27 February 2014

Accepted: 28 February 2014

Online: 30 June 2014

\section{KEYWORDS}

M sub-shell X-rays

Selective excitation

Bremsstrahlung X-rays

Variable energy photons

$\mathrm{X}$-ray tube photon source

X-ray fluorescence cross-section

\section{Introduction}

In X-ray fluorescence (XRF) studies, the probabilities of photon induced X-ray emission/production known as X-ray fluorescence cross-section $\left(\sigma^{*}\right)$ is an important most sought parameter. It is a composite parameter as product of photo ionization cross-section $(\sigma)$, fluorescence yield $(\omega)$ and fractional radiative decay rates $(F)$. The applications of low energy fluorescent $\mathrm{X}$-rays in various fields such as material science, forensic science, dosimetric computation, elemental analysis and nuclear, atomic and molecular physics etc. have raised the importance of data on $\mathrm{L}$ and $\mathrm{M}$ shell X-ray fluorescence cross sections. The experimental data for K-shell cross-sections as compared to that of $\mathrm{L}$ and $\mathrm{M}$ shells is almost well established while it is scanty for $\mathrm{M}$ and higher shells but moderate for L X-ray fluorescence cross-sections [1]. The scantiness of data on M X-ray cross-section is because of M shell structural complexities as it consists of five sub-shells. There are a number of intra-shell Coster-Kronig / Super CosterKronig transitions leading to modification of initial M sub-shell vacancy distribution from excitations. The interaction of photons of energies $<10 \mathrm{keV}$ with elements, $\mathrm{Z} \geq 70$, involves only $\mathrm{M}$ and higher shell electrons and it has raised the importance of M X-ray productions in low energy range. Moreover, to check the fine details of the atomic structure, data on XRF cross-sections for individual M X-ray line/group of lines would play a dominant role.

In the context of fluorescent X-ray measurements, the dependence of X-ray emission probability on incident photon energy requires the pre-hand knowledge of incident photon energies hence the photon sources. The widely used photon sources are radioactive sources in single/double reflection setup, X-ray tubes in double reflection set-up and synchrotron sources. The use of radioactive sources in single reflection [211] and double reflection set up [12-13] imposes limitations on energies and intensities of incident photons. The synchrotron photon sources take care of these limitations but only limited numbers of these facilities are available in the world. Therefore, $\mathrm{X}$-ray tube as photon source with photon intensities better than that from radioactive sources became the appropriate choice for the laboratory experiment.

Available M XRF measurements with X-ray tube photon sources are at some specific discrete photon energies derived from primary excitations of suitable targets in double reflection set ups [14-15]. Again this results in limitations on energies of exciting photons. Moreover, due to the complexity of M X-ray spectra, it is more difficult to measure individual line/group production cross-section for the shell. Only measurements of [16] on individual M sub-shell X-ray fluorescence cross-section are available for elements $71 \leq Z \leq 92$ at $5.96 \mathrm{keV}$. 
Table 1. Weighted M X-ray group energies for elements $\mathrm{Pt}, \mathrm{Au}, \mathrm{Pb}$, Th and $\mathrm{U}$.

\begin{tabular}{|c|c|c|c|c|c|}
\hline \multirow[t]{2}{*}{ M X-ray group } & \multicolumn{5}{|c|}{$\mathrm{E}_{\mathrm{Mg}}(\mathrm{keV})$} \\
\hline & Pt & $\mathbf{A u}$ & $\mathbf{P b}$ & Th & $\mathbf{U}$ \\
\hline $\mathrm{M} \xi$ & 1.60 & 1.66 & 1.84 & 2.35 & 2.49 \\
\hline$M \alpha \beta$ & 2.09 & 2.16 & 2.39 & 3.07 & 3.26 \\
\hline $\mathrm{M} \gamma$ & 2.33 & 2.40 & 2.65 & 3.39 & 3.58 \\
\hline $\mathrm{Mm}$ & 2.71 & 2.80 & 3.12 & 4.07 & 4.34 \\
\hline
\end{tabular}

Still, more data is required on $M$ sub-shell X-ray fluorescence cross-sections at different energies to have a better insight into atomic structure and to check theory against experiment.

In the present study, X-ray tube Bremsstrahlung has been used as photon source of desired energies simply by adjusting its anode voltages and individual M-line/group of lines $M \xi$, $\mathrm{M} \alpha \beta, \mathrm{M} \gamma$ and Mm XRF cross-sections have been measured at five different energies for each of $\mathrm{Pt}, \mathrm{Au}, \mathrm{Pb}$, Th and $\mathrm{U}$ elements. The selective creation of only $M$ shell vacancies at five energies in experimental targets has been done with photons from the tube. Since, continuous Bremsstrahlung X-rays from the tube lying between M5 edge energy of target element and the tube anode voltage were able to create $M$ sub-shell vacancies, therefore, weighted average energy $E_{\text {avg }}$ of incident tube photons was determined following a specific calculation procedure to evaluate single energy value at which the crosssections $\sigma_{M g}^{*}$ for groups of M X-rays were measured. The details of the measurements, adopted procedure, results and discussions are being given here.

\section{Experimental}

The experimental set up consisted of 100 Watt low power Neptune Rh anode X-ray tube from Oxford, USA as a photon source along with a Peltier cooled Amptek XR-100CR Si-PIN detector of resolution $\sim 220 \mathrm{eV}$ at $5.959 \mathrm{keV}$ in a $90^{\circ}$ single reflection set up (Figure 1 ). The compact geometry employed in the setup was made from a single iron block of dimensions $4 \times$ $4 \times 2.5 \mathrm{~cm}$ with $1 \mathrm{~mm}$ thick Al lining of internal surfaces of collimations and outer exposed area of the block for absorption of iron K-X rays. A beam size $\sim 0.9 \times 1.4 \mathrm{~cm}$ is allowed to impinge on the target surface. The Spec-pure metallic targets; $\mathrm{Pt}, \mathrm{Au}, \mathrm{Pb}$, Th and $\mathrm{U}$, each of diameter: $4 \mathrm{~cm}$ were used.

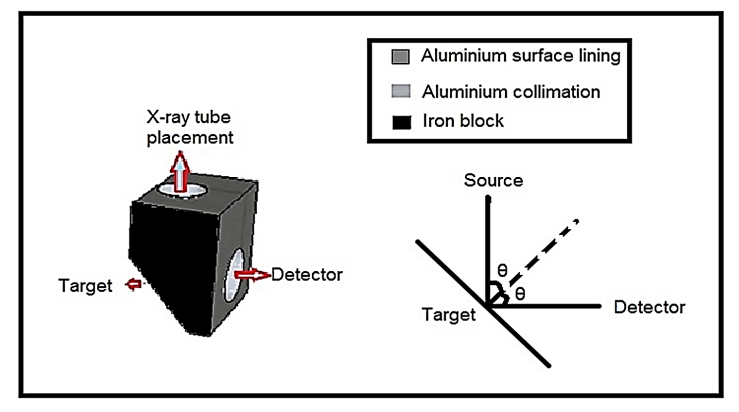

Figure 1. $90^{\circ}$ Single reflection geometry made from single iron block. (Diameter of collimation between; X-ray tube window and target $=0.8 \mathrm{~cm}$, target and detector $=1.0 \mathrm{~cm}$. Length of collimation between; X-ray tube window and target $=3.5 \mathrm{~cm}$, target and detector $=0.5 \mathrm{~cm}$ ).

Selective excitation of $M$ shell of each target was done by adjusting the tube anode voltages at five different values between the $\mathrm{L}_{3}$ and $\mathrm{M}_{1}$-edge energies of the target. The total range of excitation energy of all the targets, comprising five energies for each target, was obtained by adjusting the tube power in the range $6-14 \mathrm{kV}$ in steps. The filament current of the tube was 0.2-0.9 $\mathrm{mA}$ to maintain the dead time loses of the detector $<1 \%$. In order to assure the reproducibility of results, minimum three sets of spectra for each element and energy combination were recorded. In each measurement, the tube radiation scattered from the target was accounted by recording the spectrum with equivalent Al target [17] of the experimental one and subtracted from the target M X-ray spectrum.

Since M-shell consists of five sub-shells the X-rays from the target consist of a number of transition lines. But due to limited resolution of the set-up, the X-ray lines fall within different groups. The grouping of $\mathrm{M}$ X-rays has been done by selecting the M X-ray line energies falling in the regions of intense $M$ line \pm detector resolution. The emerged four main groups $(\mathrm{Mg})$ are $\mathrm{M} \xi, \mathrm{M} \alpha \beta, \mathrm{M} \gamma$ and $\mathrm{Mm}$. The transitions grouped under different groups are $M \xi\left(M_{4}-N_{2,3} ; M_{5}-N_{3}\right), M \alpha \beta\left(M_{5}-N_{6,7}, O_{3} ; M_{4}-N_{7}\right), M \gamma$ $\left(\mathrm{M}_{2}-\mathrm{N}_{1} ; \mathrm{M}_{3}-\mathrm{N}_{4,5}\right)$ and $\mathrm{M}_{\mathrm{m}}\left(\mathrm{M}_{3}-\mathrm{O}_{1,4,5} ; \mathrm{M}_{3}-\mathrm{N}_{6,7} ; \mathrm{M}_{2}-\mathrm{N}_{4} ; \mathrm{M}_{1}-\mathrm{N}_{2,3}\right)$.

The weighted X-ray energy of different groups $\mathrm{E}_{\mathrm{Mg}}$ were calculated using radiative transition probabilities of Chen and Crasemann [18] and level energies from tables of Storm and Israel [19]. The group energies were marked in the net subtracted spectra after their precise energy calibrations and are listed in Table 1.

The experiment was run for sufficient time to obtain the statistics of counts $<1 \%$ under various peaks of the background subtracted net spectrum. A typical set of spectra for Au and equivalent $\mathrm{Al}$ (weight of $\mathrm{Al}$ target with electron number equal to that of $\mathrm{Au}$ target weight i.e. $\mathrm{Al}(\mathrm{wt})=.(\mathrm{Z}(\mathrm{Au}) / \mathrm{Z}(\mathrm{Al}))^{*}(\mathrm{M}(\mathrm{Al}) /$ $\mathrm{M}(\mathrm{Au}))^{*}(\mathrm{Au}(\mathrm{wt})$, where $\mathrm{Z}$ and $\mathrm{M}$ represent atomic number and atomic mass, respectively) at anode voltage/filament current 9 $\mathrm{kV} / 0.2 \mathrm{~mA}$ is shown in Figure 2a. The scattered tube flux from the target comprising scattered $\mathrm{Rh} \mathrm{L}$ X-rays of tube anode at $2.94 \mathrm{keV}$ that merged with atmospheric Ar $\mathrm{K}$ X-rays are eliminated in the net background subtracted spectrum, shown in Figure 2b.

Since, the $M$ shell excitations were with continuous Bremsstrahlung photons lying in the region, $\mathrm{M}_{5}$ level edge energy to energy corresponding to the tube anode voltage, therefore, a separate experiment and calculation procedure has been followed to find a single average energy for the exciting continuous Bremsstrahlung for $\mathrm{M}$ shell excitations.

\subsection{Evaluation of weighted average energy and intensity of continuous Bremsstrahlung}

High flux output of X-ray tube is difficult to record directly with Si-PIN detector because of its dead time problem. Therefore, for each excitation, the spectrum of tube photons scattered from the aluminum (Al) target in the same set-up with the same anode voltage/filament current of the tube as in case of experimental target was processed. The continuous Bremsstrahlung regions in $\mathrm{Al}$ spectrum free from observed peaks were then fitted with a polynomial fit in origin 6.0 to have a best smooth Bremsstrahlung spectrum close to actual count values. To evaluate weighted average energy of incident flux, the fitted region above $\mathrm{M}_{5}$ edge energy of experimental target and energy corresponding to applied voltage was divided into $n$ number of strips. Each strip was of width $200 \mathrm{eV}$ (<detector resolution). A typical Al spectrum at tube power 7 $\mathrm{kV} / 0.2 \mathrm{~mA}$ is shown in Figure 3.

A procedure has been adopted to determine the intensity of incident flux $I_{n}$ in $\mathrm{n}^{\text {th }}$ strip that is falling on target area seen by the detector from the collected number of scattered count rate $N_{n}$ in the strip using extrinsic detector efficiency $\varepsilon_{(E n)}$ at the strip 


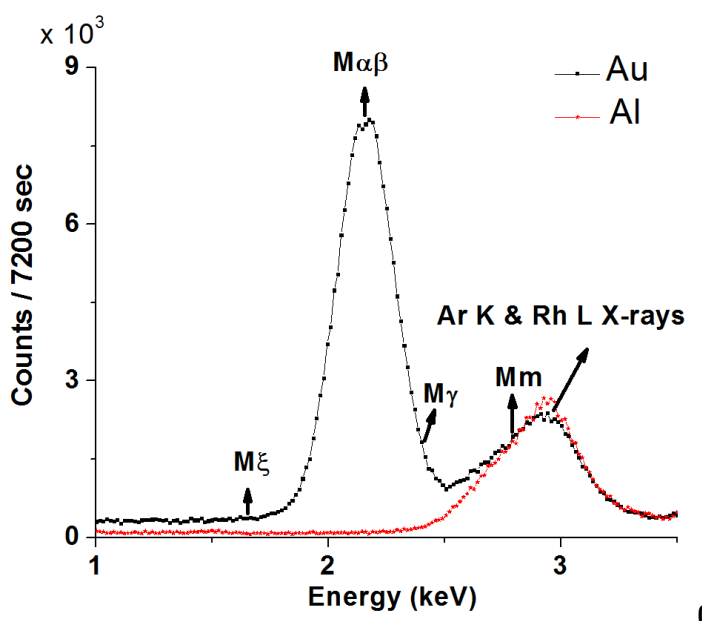

(a)

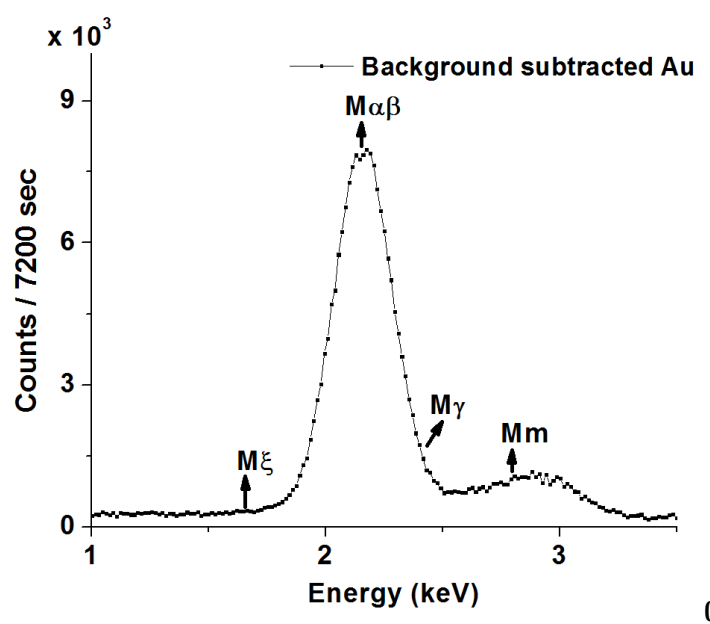

(b)

Figure 2. (a) Typical spectrum $\mathrm{Au}$ and equivalent $\mathrm{Al}$ taken at $9 \mathrm{kV} / 0.2 \mathrm{~mA}$, (b) Background subtracted net spectrum of $\mathrm{Au}$.

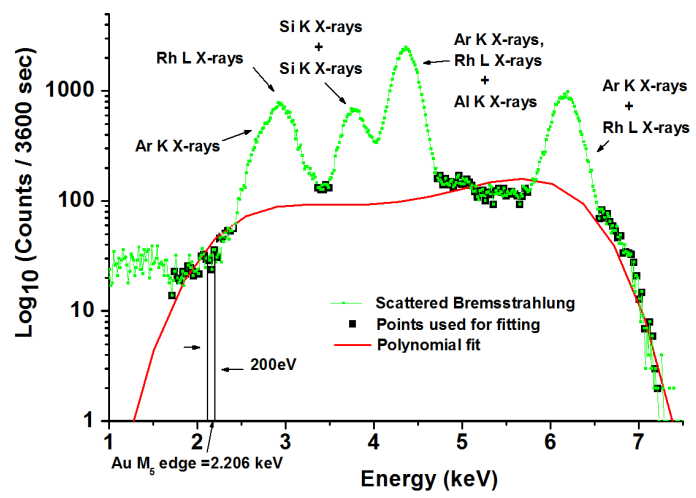

Figure 3. Polynomial fitting of scattered Bremsstrahlung in Al scatter taken at $7 \mathrm{kV} / 0.2 \mathrm{~mA}$. (Peak at $2.92 \mathrm{keV}$ is merged peak of atmospheric Ar K X-rays and scattered Rh L X-rays of tube anode, peak at $3.78 \mathrm{keV}$ is the sum peak of Si K X-rays of the Si (PIN) detector, peak at $4.35 \mathrm{keV}$ is sum peak of first peak energy and $\mathrm{Al} \mathrm{K} \mathrm{X-rays} \mathrm{and} \mathrm{peak} \mathrm{at} 6.16 \mathrm{keV}$ is sum of $\mathrm{Ar} \mathrm{K} \mathrm{X-rays} \mathrm{and}$ scattered Rh L X-rays).

mean energy $E_{\mathrm{n}}$ and self-absorption correction factor for $\mathrm{Al}$ at incident and scattered photon energies $\left[\beta_{E n}(i, e)\right]_{A l}$ from the relation

$I_{n}=\frac{\mathrm{N}_{E_{n}} \cdot M_{A l}}{\left(\sigma_{\text {total }}\left(E_{n}\right)\right)_{A l\left(90^{\circ}\right)} \cdot\left[\beta_{E_{n}}(i, e)\right]_{A l} \cdot t_{A l} \cdot \varepsilon_{\left(E_{n}\right)} \cdot A_{v}}$ where $A_{V}$ is Avogadro's number, $M_{A l}$ is molecular weight of $\mathrm{Al}$ target, $t_{A l}$ is the Al target thickness in $\mathrm{g} / \mathrm{cm}^{2} . \sigma^{\prime} s\left(E_{n}\right)$ are the coherent and incoherent scattering cross-sections of $\mathrm{Al}$ in barns/atom.

For all strips, the factor $\frac{\mathrm{A}_{\mathrm{V}}}{\mathrm{M}_{\mathrm{Al}}} \times \mathrm{t}_{\mathrm{Al}}$, number of atoms per unit area of target are same, but incoherent Klien-Nishina and coherent Rayleigh scattering cross-sections of $\mathrm{Al}$ [20] at 90, effective thickness $\beta t$ of $\mathrm{Al}$ target and extrinsic detector efficiency $\varepsilon\left(E_{n}\right)$ change due to changed strip energy and need evaluations at each strip mean energy.

Coherent and incoherent scattering cross-sections at $90^{\circ}$ at the strip mean energies were calculated using formulation and tabulations of Hubbell et al. [20] and the total scattering crosssection for $\mathrm{Al}$ at $90^{\circ}$ is evaluated as

$\left(\sigma_{\text {total }}\right)_{\mathrm{Al}\left(90^{\circ}\right)}=\left(\sigma_{\text {coh }}\right)_{\mathrm{Al}\left(90^{\circ}\right)}+\left(\sigma_{\text {inc }}\right)_{\mathrm{Al}\left(90^{\circ}\right)}$

Al self-absorption correction factor,

$\left[\beta_{\mathrm{E}_{\mathrm{n}}}(\mathrm{i}, \mathrm{e})\right]_{\mathrm{Al}}=\frac{1-\exp \left(-\left(\frac{\mu(\mathrm{i})}{\cos \theta_{\mathrm{i}}}+\frac{\mu(\mathrm{e})}{\cos \theta_{\mathrm{e}}}\right) \mathrm{t} \mathrm{Al}\right)}{\left(\frac{\mu(\mathrm{i})}{\cos \theta_{\mathrm{i}}}+\frac{\mu(\mathrm{e})}{\cos \theta_{\mathrm{e}}}\right) \mathrm{t}_{\mathrm{Al}}}$

where $\mu$ 's are Al absorption coefficients at incident $i$ and emitted $e$ photon energies and $\theta_{i}$ and $\theta_{e}$ are the angles between incident radiation \& target normal and target normal \& detector and were evaluated for $\theta_{i}=\theta_{e}=45^{\circ}$ with $\mu^{\prime}$ s values known from XCOM program [21].

At energies $<10 \mathrm{keV}$, the incoherent scattered energy is just $<200 \mathrm{eV}$ (strip width) away from incident energy, therefore, in a strip both incident and scattered energies were taken as mean energy $E_{n}$ of the strip i.e. $E_{\mathrm{n}}(\mathrm{i})=E_{\mathrm{n}}(\mathrm{e})=E_{\mathrm{n}}$.

The $\varepsilon\left(E_{n}\right)$, efficiency of detector was calculated at the strip mean energy with formulation,

$$
\begin{aligned}
& \varepsilon\left(E_{n}\right)=\exp \left[-\mu_{\text {air }}\left(E_{n}\right) t_{\text {air }}\right] \times \exp \left[-\mu_{B e}\left(E_{n}\right) t_{B e}\right] \times \\
& \left\{1-\exp \left[-\mu_{S i}\left(E_{n}\right) t_{S i}\right]\right\}
\end{aligned}
$$

where, $\mu_{a i r}, \mu_{B e}$ and $\mu_{S i}$ are the absorption coefficients of air, Be and $\mathrm{Si}$ at $\mathrm{E}_{\mathrm{n}}$ energy and $t_{a i r}, t_{B e}$ and $t_{S i}$ are air column between target and detector window, Beryllium window and detector thickness, respectively.

From Equation (1), intensity of each strip $I_{n}$ falling on the target area was evaluated and the weighted average energy of the exciting Bremsstrahlung was calculated as

$E_{\text {avg }}=\frac{\sum_{n} E_{n} I_{n}}{\sum_{n} I_{n}}$

Total intensity falling on the target,

$\mathrm{I}=\sum_{\mathrm{n}} \mathrm{I}_{\mathrm{n}}$

For experimental targets $\mathrm{Au}, \mathrm{Pt}$ and $\mathrm{Pb}$, the scattered $\mathrm{Rh} \mathrm{L}$ $\mathrm{X}$-rays at $2.88 \mathrm{keV}$ also produce $\mathrm{M}$ vacancies. But in Al scattered spectrum it is cumbersome to extract scattered $\mathrm{Rh} \mathrm{L}$ X-ray intensity from the combined atmospheric $\mathrm{Ar} \mathrm{K}$ X-rays and scattered Rh L X-rays peak. 
Table 2. List of $\mathrm{M}_{5}$-edge energies of experimental elements and K-edge energies of low $\mathrm{Z}$ elements in combination.

\begin{tabular}{llll}
\hline Experimental target & Low Z element & M5-edge(keV) & K-edge (keV) \\
\hline $\mathrm{U}$ & $\mathrm{K}$ & 3.552 & 3.607 \\
$\mathrm{Th}$ & $\mathrm{K}$ & 3.332 & 3.607 \\
$\mathrm{~Pb}$ & $\mathrm{~S}$ & 2.484 & 2.472 \\
$\mathrm{Au}$ & $\mathrm{P}$ & 2.206 & 2.144 \\
$\mathrm{Pt}$ & $\mathrm{P}$ & 2.122 & 2.144 \\
\hline
\end{tabular}

Table 3. Weighted average energies and total evaluated intensity (counts/sec in the region)at different voltages for each combination.

\begin{tabular}{|c|c|c|c|c|c|}
\hline \multirow[t]{2}{*}{ Voltage(kV) } & \multicolumn{5}{|l|}{ Evg $_{\text {aveV)/I }}$} \\
\hline & $\mathbf{P t} / \mathbf{P}$ & $\mathbf{A u} / \mathbf{P}$ & $\mathrm{Pb} / \mathrm{S}$ & Th / K & $\mathbf{U} / \mathbf{K}$ \\
\hline 6 & $3.011 / 8301$ & $3.011 / 8301$ & $3.174 / 6964$ & $4.145 / 2$ & - \\
\hline 6.5 & - & - & - & - & $4.47 / 1$ \\
\hline 8 & $3.15 / 32$ & $3.15 / 32$ & $3.46 / 23$ & $5.19 / 6$ & $5.19 / 6$ \\
\hline 9 & $3.27 / 39$ & $3.27 / 39$ & - & - & - \\
\hline 10 & $3.37 / 41$ & $3.37 / 41$ & $3.50 / 44$ & $5.27 / 11$ & $5.27 / 11$ \\
\hline 11 & $3.56 / 53$ & $3.56 / 53$ & - & - & - \\
\hline 12 & - & - & $3.95 / 66$ & $6.29 / 20$ & $6.29 / 20$ \\
\hline 13 & - & - & $4.46 / 58$ & - & - \\
\hline 14 & - & - & - & $7.38 / 31$ & $7.38 / 31$ \\
\hline
\end{tabular}

Therefore, to determine the total intensity (Rh L X-ray + Bremsstrahlung) in each strip of the combined peak region, the ratio of total intensity/ Bremsstrahlung intensity was determined from the direct tube output, recorded with filament current $0.01-0.05 \mathrm{~mA}$ and highly collimated detector placed at the position of Al target and, in turn, $I_{n}$ in the strip was multiplied with the ratio to include the contribution of scattered Rh L X-rays in production of M vacancies.

Hence the weighted average energy and intensity values were calculated and have been used as characters of incident exciting flux from X-ray tube.

\subsection{Calculations of $M g X$-ray fluorescence cross-sections}

With counts $\mathrm{N}_{\mathrm{Mg}}$ under the $\mathrm{Mg}_{\mathrm{g}}$ group of X-rays $\sigma_{\mathrm{Mg}}^{*}$ the fluorescence cross-section for $\mathrm{Mg}$ group of $\mathrm{X}$-rays was calculated from the relation,

$$
\sigma_{M g}^{*}=\frac{N_{M_{g}} M_{M}}{A_{v}(t \cdot \beta)_{M g} \cdot \varepsilon_{M g} \cdot S_{0} \cdot G}
$$

Where $S_{0} G$ accounts for incident photons falling upon the target area seen by the detector with absorption of incident and emitted photons in the air.

The factor $S_{0} G=S_{0} \frac{\Omega_{1}}{4 \pi} \frac{\Omega_{2}}{4 \pi} a_{\text {air }}{ }^{(i)} \cdot a_{\text {air }}{ }^{(e)}$, with $S_{0}$ as incident photon flux from the source; $\Omega_{1} \& \Omega_{2}$ target-source \& targetdetector solid angles; aair $(\mathrm{i})$, aair $(\mathrm{e})$ the absorption of the incident photon in air column between source and target and of emitted photons in the air column between target and detector, was determined for each experimental target in the present set-up at each excitation energy by irradiating the selected low $\mathrm{Z}$ target to excite its $\mathrm{K}$ shell in the same set-up with same flux. The selection of low $\mathrm{Z}$ for each experimental target was made such that $\mathrm{K}$ edge energy of low $\mathrm{Z}$ target was equal to $\mathrm{M}_{5}$ edge energy of experimental target nearly within the detector resolution. Table 2 shows the combination of low $\mathrm{Z}$ target and experimental targets.

Wherever the difference in the $\mathrm{K}$-edge and $\mathrm{M}_{5}$-edge energies were greater than $200 \mathrm{eV}$, the width of the strip at lowest energy was increased exactly equal to the difference energy (e.g. in case of (Th, K) it was made $275 \mathrm{eV}$ ).

In this way, the weighted average energy and intensity remained the same for each combination and are being given in Table 3.

For K excitations of low Z targets,

$S_{\mathrm{o}} G=\frac{N_{K} \cdot M_{K}}{A_{V}(t . \beta)_{K} \varepsilon_{K} \sigma^{*}{ }_{K}}$ where the terms on R.H.S. are for K X-ray targets.

From relations (7) and (8)

$$
\sigma_{\mathrm{Mg}}^{*}=\frac{\mathrm{N}_{\mathrm{Mg}} \cdot \mathrm{M}_{\mathrm{M}} \cdot(\mathrm{t} \cdot \beta)_{\mathrm{K}} \cdot \varepsilon_{\mathrm{K}} \cdot \sigma_{\mathrm{K}}^{*}}{\mathrm{~N}_{\mathrm{K}} \cdot \mathrm{M}_{\mathrm{K}} \cdot(\mathrm{t} \cdot \beta)_{\mathrm{Mg}} \cdot \varepsilon_{\mathrm{Mg}}}
$$

For each $\sigma_{M g}^{*}$ calculation, $\beta^{\prime} s$ and $\varepsilon^{\prime} s$ were evaluated as mentioned in relations (3) \& (4) for desired incident and emitted energies. K X-ray production cross-section $\sigma_{\mathrm{K}}^{*}$ has been known at the weighted average incident energy from computer code KCSPIF developed earlier in our laboratory [22].

Peak area extraction for $g^{\text {th }}(g=\xi, \alpha \beta, \gamma)$ group of M X-rays has been done by marking the centroid of groups on a calibrated energy scale. In case of hump, the gross area of half peak on the side of centroid that is comparatively free from adjacent peak interference was selected by highlighting the channels under half peak. Doubling this area gives us the total gross area for the gth group. For background subtraction, lowest background counts on that side was multiplied by the total number of channels covered by the group and subtracted from the gross area. A typical illustration of extracted different M Xray peaks for $\mathrm{Au}$ in background subtracted spectrum at $9 \mathrm{kV} /$ $0.2 \mathrm{~mA}$ tube power is given in Figure 4 that shows the replication of different peaks with Gaussian fit with same counts under each peak. The spectrum consists of many peaks say $\mathrm{Mg}\left(\mathrm{g}=\xi, \delta, \alpha, \beta, \zeta, \gamma, \mathrm{m}_{1}\right.$ and $\left.\mathrm{m}_{2}\right)$ but in the present method only four group were extracted as the individual peaks could not be resolved further due to poor detector resolution.

After determining the peak area under various peaks, target self-absorption corrections factors and detector efficiency at element energies and production cross-section for low $\mathrm{Z}$ element used in combination, $\mathrm{M}$ sub-shell $\mathrm{X}$-ray fluorescence cross-section have been evaluated and are listed in Table 4.

\section{Results and discussion}

The measured experimental M X-ray group cross-sections are listed in Table 4. The error in the values is the squared root sum of uncertainties in different individual parameters used to measure X-ray production cross-section as target selfabsorption correction factor ( 7\%), detector efficiency (5-7\%), peak area extraction $\left(0.1\right.$ to $10 \%$ for $\mathrm{M} \xi$ and $\mathrm{M}_{\mathrm{m}},<0.5 \%$ for $M \alpha \beta,<1 \%$ for $M \gamma$ ) etc.

The authenticity and reliability of present method of measurements and calculations has been judged in terms L Xray fluorescence cross-section measurements as data on $\mathrm{L}$ cross-section is moderate as compared to that for M X-rays. 
Table 4. List of measured and theoretical M X-ray production cross-sections.

\begin{tabular}{|c|c|c|c|c|c|c|c|c|c|c|}
\hline \multirow[t]{3}{*}{ Elements } & \multirow[t]{3}{*}{ Voltage (kV) } & \multirow{3}{*}{$\begin{array}{l}\text { Incident } \\
\text { Energy }\end{array}$} & \multicolumn{8}{|c|}{ Cross-section (b/atom) } \\
\hline & & & \multicolumn{2}{|l|}{$\underline{\boldsymbol{\sigma}_{\mathrm{M} \xi}}$} & \multicolumn{2}{|l|}{$\sigma_{M \alpha \beta}$} & \multicolumn{2}{|l|}{$\sigma_{M \gamma}$} & \multicolumn{2}{|l|}{$\boldsymbol{\sigma}_{\mathrm{Mm}}$} \\
\hline & & & $\begin{array}{l}\text { Exp. } \\
\text { (Error) }\end{array}$ & $\begin{array}{l}\text { Theory } \\
\text { DF/ DHS. }\end{array}$ & $\begin{array}{l}\text { Exp. } \\
\text { (Error) }\end{array}$ & $\begin{array}{l}\text { Theory } \\
\text { DF/ DHS. }\end{array}$ & $\begin{array}{l}\text { Exp. } \\
\text { (Error) }\end{array}$ & $\begin{array}{l}\text { Theory } \\
\text { DF/ DHS. }\end{array}$ & $\begin{array}{l}\text { Exp. } \\
\text { (Error) }\end{array}$ & $\begin{array}{l}\text { Theory } \\
\text { DF/ DHS. }\end{array}$ \\
\hline \multirow[t]{5}{*}{$\overline{\mathrm{Pt}}$} & 6 & 3.01 & $494(49)$ & $\begin{array}{l}554 / \\
516\end{array}$ & $11259(788)$ & $\begin{array}{l}12059 / \\
11230\end{array}$ & $275(19)$ & $\begin{array}{l}339 / \\
302\end{array}$ & $38(4)$ & $\begin{array}{l}36 / \\
32\end{array}$ \\
\hline & 8 & 3.15 & $422(42)$ & $\begin{array}{l}538 / \\
501\end{array}$ & $11139(780)$ & $\begin{array}{l}11603 / \\
10804\end{array}$ & $336(23)$ & $\begin{array}{l}347 / \\
309\end{array}$ & $135(14)$ & $\begin{array}{l}134 / \\
118\end{array}$ \\
\hline & 9 & 3.27 & $354(35)$ & $\begin{array}{l}491 / \\
457\end{array}$ & $10168(712)$ & $\begin{array}{l}10584 / \\
9855\end{array}$ & $324(23)$ & $\begin{array}{l}326 / \\
290\end{array}$ & $104(10)$ & $\begin{array}{l}128 / \\
112\end{array}$ \\
\hline & 10 & 3.37 & $469(47)$ & $\begin{array}{l}478 / \\
445\end{array}$ & $9346(654)$ & $\begin{array}{l}10314 / \\
9604\end{array}$ & $319(22)$ & $\begin{array}{l}358 / \\
319\end{array}$ & $157(16)$ & $\begin{array}{l}182 / \\
160\end{array}$ \\
\hline & 11 & 3.56 & $312(31)$ & $\begin{array}{l}418 / \\
389\end{array}$ & $7050(494)$ & $\begin{array}{l}9015 / \\
8394\end{array}$ & $231(16)$ & $\begin{array}{l}327 / \\
291\end{array}$ & $128(13)$ & $\begin{array}{l}169 / \\
148\end{array}$ \\
\hline \multirow[t]{5}{*}{$\overline{\mathrm{Au}}$} & 6 & 3.01 & $511(51)$ & $\begin{array}{l}606 / \\
531\end{array}$ & $11886(832)$ & $\begin{array}{l}13466 / \\
11822\end{array}$ & $300(21)$ & $\begin{array}{l}377 / \\
341\end{array}$ & $64(6)$ & $\begin{array}{l}61 / \\
55\end{array}$ \\
\hline & 8 & 3.15 & $480(48)$ & $\begin{array}{l}533 / \\
500\end{array}$ & $9476(663)$ & $\begin{array}{l}11856 / \\
11142\end{array}$ & $384(27)$ & $\begin{array}{l}368 / \\
329\end{array}$ & $63(6)$ & $\begin{array}{l}60 / \\
53\end{array}$ \\
\hline & 9 & 3.27 & $385(38)$ & $\begin{array}{l}582 / \\
547\end{array}$ & $10474(733)$ & $\begin{array}{l}12723 / \\
11950\end{array}$ & $435(30)$ & $\begin{array}{l}422 / \\
377\end{array}$ & $196(20)$ & $\begin{array}{l}292 / \\
256\end{array}$ \\
\hline & 10 & 3.37 & $460(46)$ & $\begin{array}{l}586 / \\
550\end{array}$ & $9678(677)$ & $\begin{array}{l}12936 / \\
12154\end{array}$ & $404(28)$ & $\begin{array}{l}405 / \\
362\end{array}$ & $164(16)$ & $\begin{array}{l}161 / \\
142\end{array}$ \\
\hline & 11 & 3.56 & $501(50)$ & $\begin{array}{l}448 / \\
421\end{array}$ & $11306(791)$ & $\begin{array}{l}9905 / \\
9306\end{array}$ & $319(22)$ & $\begin{array}{l}379 / \\
339\end{array}$ & $246(25)$ & $\begin{array}{l}203 / \\
180\end{array}$ \\
\hline \multirow[t]{5}{*}{$\mathrm{Pb}$} & 6 & 3.17 & $565(57)$ & $\begin{array}{l}659 / \\
632\end{array}$ & $14646(1025)$ & $\begin{array}{l}15394 / \\
14748\end{array}$ & $202(14)$ & $\begin{array}{l}447 / \\
377\end{array}$ & $111(11)$ & $\begin{array}{l}88 / \\
74\end{array}$ \\
\hline & 8 & 3.46 & $350(35)$ & $\begin{array}{l}528 / \\
506\end{array}$ & $9018(631)$ & $\begin{array}{l}12352 / \\
11834\end{array}$ & $289(20)$ & $\begin{array}{l}398 / \\
335\end{array}$ & $95(9)$ & $\begin{array}{l}78 / \\
66\end{array}$ \\
\hline & 10 & 3.5 & $486(49)$ & $\begin{array}{l}513 / \\
491\end{array}$ & $8170(572)$ & $\begin{array}{l}11996 / \\
11493\end{array}$ & $87(6)$ & $\begin{array}{l}391 / \\
330\end{array}$ & $98(10)$ & $\begin{array}{l}65 / \\
77\end{array}$ \\
\hline & 12 & 3.95 & $337(34)$ & $\begin{array}{l}428 / \\
411\end{array}$ & $7356(515)$ & $\begin{array}{l}9938 / \\
9523\end{array}$ & $62(4)$ & $\begin{array}{l}386 / \\
326\end{array}$ & $143(14)$ & $\begin{array}{l}179 / \\
206\end{array}$ \\
\hline & 13 & 4.46 & $217(22)$ & $\begin{array}{l}319 / \\
306 \\
\end{array}$ & $5298(371)$ & $\begin{array}{l}7405 / \\
7095\end{array}$ & $63(4)$ & $\begin{array}{l}329 / \\
278 \\
\end{array}$ & $95(9)$ & $\begin{array}{l}131 / \\
174 \\
\end{array}$ \\
\hline \multirow[t]{5}{*}{$\overline{T h}$} & 6 & 4.15 & $691(55)$ & $\begin{array}{l}610 / \\
596\end{array}$ & $21273(1489)$ & $\begin{array}{l}15641 / \\
15468\end{array}$ & $668(53)$ & $\begin{array}{l}593 / \\
551\end{array}$ & - & - \\
\hline & 8 & 5.19 & $373(30)$ & $\begin{array}{l}387 / \\
378\end{array}$ & $11210(785)$ & $\begin{array}{l}9844 / \\
9747\end{array}$ & 484(39) & $\begin{array}{l}520 / \\
480\end{array}$ & - & - \\
\hline & 10 & 5.27 & $365(29)$ & $\begin{array}{l}314 / \\
364\end{array}$ & 11103(777) & $\begin{array}{l}9471 / \\
9377\end{array}$ & $505(40)$ & $\begin{array}{l}506 / \\
467\end{array}$ & - & - \\
\hline & 12 & 6.29 & $275(22)$ & $\begin{array}{l}238 / \\
232\end{array}$ & $7635(534)$ & $\begin{array}{l}6043 / \\
5984\end{array}$ & $386(31)$ & $\begin{array}{l}368 / \\
340\end{array}$ & - & - \\
\hline & 14 & 7.38 & $171(14)$ & $\begin{array}{l}158 / \\
154\end{array}$ & $4700(329)$ & $\begin{array}{l}4009 / \\
3970\end{array}$ & $263(21)$ & $\begin{array}{l}274 / \\
253 \\
\end{array}$ & - & - \\
\hline \multirow[t]{5}{*}{$\overline{\mathrm{U}}$} & 6.5 & 4.47 & $556(44)$ & $\begin{array}{l}567 / \\
571\end{array}$ & $15276(1069)$ & $\begin{array}{l}15025 / \\
15125\end{array}$ & $686(55)$ & $\begin{array}{l}588 / \\
559\end{array}$ & - & - \\
\hline & 8 & 5.19 & $385(31)$ & $\begin{array}{l}381 / \\
384\end{array}$ & $9239(647)$ & $\begin{array}{l}10126 / \\
10190\end{array}$ & $452(36)$ & $\begin{array}{l}463 / \\
440\end{array}$ & - & - \\
\hline & 10 & 5.27 & $385(31)$ & $\begin{array}{l}400 / \\
404\end{array}$ & $9168(642)$ & $\begin{array}{l}10493 / \\
10580\end{array}$ & $528(42)$ & $\begin{array}{l}490 / \\
466\end{array}$ & - & - \\
\hline & 12 & 6.29 & $308(25)$ & $\begin{array}{l}266 / \\
269\end{array}$ & $6243(437)$ & $\begin{array}{l}6994 / \\
7050\end{array}$ & $415(33)$ & $\begin{array}{l}408 / \\
388\end{array}$ & - & - \\
\hline & 14 & 7.38 & 208(17) & $\begin{array}{l}177 / \\
178\end{array}$ & $3936(276)$ & $\begin{array}{l}4641 / \\
4678\end{array}$ & $271(22)$ & $\begin{array}{l}304 / \\
290\end{array}$ & - & - \\
\hline
\end{tabular}

*"-“: Not measured at these energies.

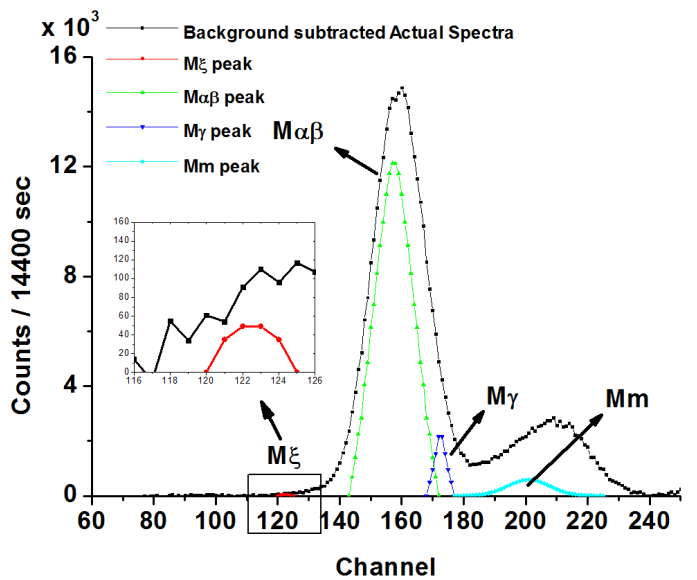

Figure 4. Various $\mathrm{M} X$-ray groups $(\mathrm{M} \xi, \mathrm{M} \alpha \beta, \mathrm{M} \gamma, \mathrm{Mm})$ resolved for $\mathrm{Au}$ at $9 \mathrm{kV} / 0.2 \mathrm{~mA}$. 
Table 5. List of measured $L \ell, L \alpha, L \beta$ and $L \gamma$ fluorescence cross-sections along with semi-empirical/theoretical values generated from software LCSGEN [23] for Ag at $4.466 \mathrm{keV}$ photon energy.

\begin{tabular}{llll}
\hline L X-ray group, Lg & $\sigma_{L g}^{*}$ (b/atom) & & Theoretical \\
\cline { 2 - 4 } & Experimental & Semi-empirical & 193 \\
$\mathrm{~L} \ell$ & $218(15)$ & 169 & 5328 \\
$\mathrm{~L} \alpha$ & $4664(326)$ & 4647 & 2910 \\
$\mathrm{~L} \beta$ & $2494(175)$ & 2793 & 260 \\
$\mathrm{~L} \gamma$ & $237(17)$ & 259 & 250 \\
\hline
\end{tabular}

$\sigma_{\mathrm{M} \xi}^{*}=\left[\sigma_{4}^{\mathrm{M}}+\mathrm{f}_{34}^{\mathrm{M}} \sigma_{3}^{\mathrm{M}}+\left(\mathrm{f}_{24}^{\mathrm{M}}+\mathrm{f}_{23}^{\mathrm{M}} \mathrm{f}_{34}^{\mathrm{M}}\right) \sigma_{2}^{\mathrm{M}}+\left(\mathrm{f}_{14}^{\mathrm{M}}+\mathrm{f}_{13}^{\mathrm{M}} \mathrm{f}_{34}^{\mathrm{M}}+\mathrm{f}_{12}^{\mathrm{M}} \mathrm{f}_{24}^{\mathrm{M}}+\mathrm{f}_{12}^{\mathrm{M}} \mathrm{f}_{23}^{\mathrm{M}} \mathrm{f}_{34}^{\mathrm{M}}\right) \sigma_{1}^{\mathrm{M}}\right] \omega_{4}^{\mathrm{M}} \mathrm{F}_{4 \xi}^{\mathrm{M}}+$
$\left[\begin{array}{l}\sigma_{5}^{\mathrm{M}}+\mathrm{f}_{45}^{\mathrm{M}} \sigma_{4}^{\mathrm{M}}+\left(\mathrm{f}_{35}^{\mathrm{M}}+\mathrm{f}_{34}^{\mathrm{M}} \mathrm{f}_{45}^{\mathrm{M}}\right) \sigma_{3}^{\mathrm{M}}+\left(\mathrm{f}_{25}^{\mathrm{M}}+\mathrm{f}_{24}^{\mathrm{M}} \mathrm{f}_{45}^{\mathrm{M}}+\mathrm{f}_{23}^{\mathrm{M}} \mathrm{f}_{35}^{\mathrm{M}}+\mathrm{f}_{23}^{\mathrm{M}} \mathrm{f}_{34}^{\mathrm{M}} \mathrm{f}_{45}^{\mathrm{M}}\right) \sigma_{2}^{\mathrm{M}}+ \\ \left(\mathrm{f}_{15}^{\mathrm{M}}+\mathrm{f}_{14}^{\mathrm{M}} \mathrm{f}_{45}^{\mathrm{M}}+\mathrm{f}_{13}^{\mathrm{M}} \mathrm{f}_{35}^{\mathrm{M}}+\mathrm{f}_{12}^{\mathrm{M}} \mathrm{f}_{25}^{\mathrm{M}}+\mathrm{f}_{13}^{\mathrm{M}} \mathrm{f}_{34}^{\mathrm{M}} \mathrm{f}_{45}^{\mathrm{M}}+\mathrm{f}_{12}^{\mathrm{M}} \mathrm{f}_{24}^{\mathrm{M}} \mathrm{f}_{45}^{\mathrm{M}}+\mathrm{f}_{12}^{\mathrm{M}} \mathrm{f}_{23}^{\mathrm{M}} \mathrm{f}_{35}^{\mathrm{M}}+\mathrm{f}_{12}^{\mathrm{M}} \mathrm{f}_{23}^{\mathrm{M}} \mathrm{f}_{34}^{\mathrm{M}} \mathrm{f}_{45}^{\mathrm{M}}\right) \sigma_{1}^{\mathrm{M}}\end{array}\right] \omega_{5}^{\mathrm{M}} \mathrm{F}^{\mathrm{M}}{ }_{5 \xi}$

$$
\sigma_{M \alpha \beta}^{*}=\left[\sigma_{4}^{M}+f_{34}^{M} \sigma_{3}+\left(f_{24}^{M}+f_{23}^{M} f_{34}^{M}\right) \sigma_{2}^{M}+\left(f_{14}^{M}+f_{13}^{M} f_{34}^{M}+f_{12}^{M} f_{24}^{M}+f_{12}^{M} f_{23}^{M} f_{34}^{M}\right) \sigma_{1}^{M}\right] \omega_{4}^{M} F_{4 \alpha \beta}^{M}+
$$$$
\left[\begin{array}{l}
\sigma_{5}^{\mathrm{M}}+\mathrm{f}_{45}^{\mathrm{M}} \sigma_{4}^{\mathrm{M}}+\left(\mathrm{f}_{35}^{\mathrm{M}}+\mathrm{f}_{34}^{\mathrm{M}} \mathrm{f}_{45}^{\mathrm{M}}\right) \sigma_{3}^{\mathrm{M}}+\left(\mathrm{f}_{25}^{\mathrm{M}}+\mathrm{f}_{24}^{\mathrm{M}} \mathrm{f}_{45}^{\mathrm{M}}+\mathrm{f}_{23}^{\mathrm{M}} \mathrm{f}_{35}^{\mathrm{M}}+\mathrm{f}_{23}^{\mathrm{M}} \mathrm{f}_{34}^{\mathrm{M}} \mathrm{f}_{45}^{\mathrm{M}}\right) \sigma_{2}^{\mathrm{M}} \\
+\left(\mathrm{f}_{15}^{\mathrm{M}}+\mathrm{f}_{14}^{\mathrm{M}} \mathrm{f}_{45}^{\mathrm{M}}+\mathrm{f}_{13}^{\mathrm{M}} \mathrm{f}_{35}^{\mathrm{M}}+\mathrm{f}_{12}^{\mathrm{M}} \mathrm{f}_{25}^{\mathrm{M}}+\mathrm{f}_{13}^{\mathrm{M}} \mathrm{f}_{34}^{\mathrm{M}} \mathrm{f}_{45}^{\mathrm{M}}+\mathrm{f}_{12}^{\mathrm{M}} \mathrm{f}_{24}^{\mathrm{M}} \mathrm{f}_{45}^{\mathrm{M}}+\mathrm{f}_{12}^{\mathrm{M}} \mathrm{f}_{23}^{\mathrm{M}} \mathrm{f}_{35}^{\mathrm{M}}+\mathrm{f}_{12}^{\mathrm{M}} \mathrm{f}_{23}^{\mathrm{M}} \mathrm{f}_{34}^{\mathrm{M}} \mathrm{f}_{45}^{\mathrm{M}}\right) \sigma_{1}^{\mathrm{M}}
\end{array}\right] \omega_{5}^{\mathrm{M}} \mathrm{F}_{5 \alpha \beta}^{\mathrm{M}}
$$$$
\sigma_{M \gamma}^{*}=\left[\sigma_{3}^{M}+f_{23}^{M} \sigma_{2}^{M}+\left(f_{13}^{M}+f_{12}^{M} f_{23}^{M}\right) \sigma_{1}^{M}\right] \omega_{3}^{M} F_{3 \gamma}^{M}+\left[\sigma_{2}^{M}+f_{12}^{M} \sigma_{1}^{M}\right] \omega_{2}^{M} F_{2 \gamma}^{M}
$$$$
\sigma_{\mathrm{Mm}}^{*}=\left[\sigma_{3}^{\mathrm{M}}+\mathrm{f}_{23}^{\mathrm{M}} \sigma_{2}^{\mathrm{M}}+\left(\mathrm{f}_{13}^{\mathrm{M}}+\mathrm{f}_{12}^{\mathrm{M}} \mathrm{f}_{23}^{\mathrm{M}}\right) \sigma_{1}^{\mathrm{M}}\right] \omega_{3}^{\mathrm{M}} \mathrm{F}_{3 \mathrm{~m}}^{\mathrm{M}}+\left[\sigma_{2}^{\mathrm{M}}+\mathrm{f}_{12}^{\mathrm{M}} \sigma_{1}^{\mathrm{M}}\right] \omega_{2}^{\mathrm{M}} \mathrm{F}_{2 \mathrm{~m}}+\sigma_{1}^{\mathrm{M}} \omega_{1}^{\mathrm{M}} \mathrm{F}_{1 \mathrm{~m}}^{\mathrm{M}}
$$

Therefore, the measurements on $\mathrm{Ag} \mathrm{L} \mathrm{X-rays} \mathrm{at} 6.5 \mathrm{kV}$ anode voltage i.e. $E_{\text {avg }}=4.466 \mathrm{keV}$ were performed with potassium as $\mathrm{K} \mathrm{X}$-ray target for incident flux normalization as the edge energies 3.351 and $3.607 \mathrm{keV}$ for $\mathrm{L}_{3}$ of $\mathrm{Ag}$ and $\mathrm{K}$ of potassium are just $256 \mathrm{eV}$ apart. The measured cross-sections with $7 \%$ uncertainties for $\mathrm{L} \ell, \mathrm{L} \alpha, \mathrm{L} \beta$ and $\mathrm{L} \gamma$ group of Ag along with semi-empirical/theoretical values generated from software LCSGEN [23] are listed in Table 5.

The fair agreement of measured values within uncertainties with semi-empirical/theoretical values supports the present method of measurement and result evaluation procedure.

At this stage no experimental or theoretical values of the cross-sections at such low energies are available for comparison and to check the present measurements. Therefore, theoretical cross-section values at these energies were evaluated from the available tabulated data on fine parameters. Two sets of fluorescence yields and fractional radiative decay rates based on DHS and DF models were used in the formulations (10)-(13).

Two sets of theoretical values of M XRF cross-sections based on DF and DHS models have been calculated. In first set DF model based fluorescence [24] and fractional decay rates were used [25]. In the second set, DHS model based fluorescence yields [24] and fractional radiative decay rates were used [26]. In both the sets Coster-Kronig transition yields of Chauhan and Puri [24] and photo ionization crosssections $\sigma_{i}^{M}$ of Scofield [27] were used. The calculated theoretical values are also listed in Table 4.
The comparison of measured values of M X-ray production cross-section for the groups $\mathrm{M} \xi, \mathrm{M} \alpha \beta, \mathrm{M} \gamma$ and $\mathrm{Mm}$ for $\mathrm{Pt}, \mathrm{Au}, \mathrm{Pb}$, Th and $U$ with the calculated theoretical values based on DF and DHS models shows the experimental values of the crosssections, generally, agree with the theoretical values within experimental uncertainties. An overview points closeness of present results with DHS model based values as compared to those based upon DF model.

For Th and U, measurements could not be possible for $\mathrm{Mm}$ group as it falls in the region of Bramsstrahlung where some spurious peaks are there from the experimental set-up. So, the chances of accurate peak area extraction become rare. Otherwise, the results are almost overlapping with theory except for $\mathrm{M}_{\alpha \beta}$ of $\mathrm{Th}$. In case of $\mathrm{Pb}$ deviations are on higher side, even in case of $\mathrm{M}_{m}$ and $\mathrm{M} \gamma$ these are more than $50 \%$ and in some rare cases agreement is very good. For $\mathrm{Au}$ and $\mathrm{Pt}$, overall agreement is very good except at energy $3.56 \mathrm{keV}$ corresponding to $11 \mathrm{kV}$ anode voltage in $\mathrm{Pt}$.

From all the above comparisons, it is justified that the present method of analysis for XRF cross-section measurements is compatible with the existing methods in literature as mentioned in the introduction section. So far in literature, to the best of authors' knowledge such approach to quantify continuous Bremsstrahlung in terms of weighted average energy and intensity has not been followed for similar work but present measurements lead to the confidence to make use of such an approach. The approach resulted in measurements at such low energies 3.01-7.38 keV those are not possible/difficult 
with conventionally available radioactive sources/synchrotron sources.

\section{Conclusion}

The quantification of continuous Bremssrahlung in terms of weighted average energy and intensity that produced L/M Xray fluorescence cross-sections fairly supported by theoretical or semi-empirical values can be used confidently in future for XRF studies. The approach is capable of measurements at such low energies 3.01-7.38 keV those are not possible/difficult with conventionally available radioactive sources/ synchrotron sources.

\section{Acknowledgments}

The financial assistance from BRNS, Government of India in the form of project grant (Ref no: 2007/37/6/BRNS) for this work is highly acknowledged. Ms. Sheenu Gupta and Ms. Gurpreet Kaur acknowledge the meritorious fellowship from University Grand Commission, New Delhi, India.

\section{References}

[1]. Campbell, J. L. IRPS Bulletin 2010, 24, 17-30.

[2]. Shatendra, K.; Singh, N.; Mittal, R.; Allawadhi, K. L.; Sood, B. S. X-ray Spectrom. 1985, 14, 195-198.

[3]. Garg, R. R.; Singh, S.; Shahi, J. S.; Mehta, D.; Singh, N.; Trehan, P. N.; Kumar, S.; Garg, M. L.; Mangal, P. C. X-ray Spectrom. 1991, 20, 91-95.

[4]. Puri, S.; Mehta, D.; Chand, B.; Singh, N.; Mangal, P. C.; Trehan, P. N. Nucl. Instrum. Meth. B 1993, 73, 319-323.

[5]. Ertugrul, M.; Z. Phys D Atom. Mol. Cl. 1996, 38, 91-94

[6]. Durak, R.; Ozdemir, Y. Spectrochim. Acta B 2001, 56, 455-464.

[7]. Apaydin, G.; Tirasoglu, E.; Cevik, U.; Ertugrul, B.; Baltas,H.; Ertugrul, M.; Kobya, A. I. Radiat. Phys. Chem. 2005, 72, 549-554.

[8]. Ozdemir, Y. Nucl. Instrum. Meth. B 2007, 256, 581-585

[9]. Apaydin, G.; Tirasoglu, E.; Sogut, E. Eur. Phys. J. D 2008, 46, 487-492.

[10]. Kucukonder, A.; Sogut, O.; Dozen, C.; Durdu, B. G. Eur. Phys. J. D 2008, 46, 37-39.

[11]. Han, I.; Sahin, Z.; Demir, L.; Kacal, M. Balkan Phys. Lett. 2009, 16, 161031-161038.

[12]. Mann, K. S.; Singh, N.; Mittal, R.; Allawadhi, K. L.; Sood, B. S. J. Phys. B 1990, 23, 2497-2504.

[13]. Allawadhi, K. L.; Sood, B. S.; Mittal, R.; Singh, N.; Mann, K. S. J. Phys. B 1994, 27, 15-18.

[14]. Rao, D. V.; Cesareo, R.; Gigante, G. E. Radiat. Phys. Chem. 1995, 46, 17 320.

[15]. Rao, D. V.; Cesareo, R.; Gigante, G. E. Nucl. Instrum. Meth. B 1996, 108, 227-232.

[16]. Sharma, M.; Sharma, V.; Kumar, S.; Puri, S.; Singh, N. Radiat. Phys. Chem. 2006, 75, 1503-1509.

[17]. Mann, K. S.; Singh, N.; Mittal, R.; Allawadhi, K. L.; Sood, B. S. J. Phys. B. 1990, 23, 3521-3530.

[18]. Chen, M. H.; Crasemann, B. Phys. Rev. A 1984, 30, 170-176.

[19]. Storm, E.; Israel, H. I. Nucl. Data Tables A 1970, 7, 565-681.

[20]. Hubbel, J. H.; Veigele,J.Wm.; Briggs, E. A.; Brown, R. T.; Cromer, D. T.; Howerton, R. J. J. Phys. Chem. 1975, 4, 471-538.

[21]. Berger, M. J.; Hubbell, J. H. XCOM version 3.1, National Bureau of Standards, Gaithersburg, MD, USA, 1999.

[22]. Bansal, M.; Mittal, R. Radiat. Phys. Chem. 2009, 79, 583-593.

[23]. Mittal, R.; Vandana; Singh, M. , J. Quant. Spectros. Radiat. Trans. 2001, 68, 593-609.

[24]. Chauhan, Y.; Puri, S. At. Data Nucl. Data Tables 2008, 94, 38-49.

[25]. Chen, M. H.; Crasemann, B.; Mark, H. Phys. Rev. A 1980, 21, 449-453

[26]. Bhalla, C. P. J. Phys. B. 1970, 3, 916-924.

[27]. Scofield, J. H. Lawrence Livermore Laboratory UCRL Report No. 51362 (unpublished), 1973. 